Journal of Engineering and Applied Sciences 14 (9): 2882-2890, 2019

ISSN: 1816-949X

(C) Medwell Journals, 2019

\title{
Nearest Destination Based Coordinated Delivery Service in Trade Center
}

\author{
Purba Daru Kusuma \\ School of Electrical Engineering, Telkom University, Bandung, Indonesia
}

\begin{abstract}
One logistic problem in many trade centers is each merchant must have its own delivery unit. This condition occurs in many trade centers that sell products that customers cannot bring it by themselves such as electronics, furniture or machineries. By having their own delivery units, merchants can deliver their ordered products independently. Unfortunately having its own delivery unit needs investment, operational and maintenance costs. Meanwhile, the utility of delivery unit will fluctuate. Based on this problem, in this research, we propose new coordinated model for delivery system that suitable for trade center characteristics. In this research, besides delivery time, we also concern on installation time. This model is developed by using nearest destination method. In this research, the observed parameters are total travel distance, total travel time, success ratio and number of vehicles. Meanwhile, the adjusted parameters are number of merchants, number of delivery orders, number of goods, speed and installation time. Based on the test result, it is shown that the proposed coordinated model performs better than the non coordinated one, especially, in reducing the total travel time and total travel distance.
\end{abstract}

Key words: Logistic, trade center, delivery system, nearest destination, coordinated model, cement

\section{INTRODUCTION}

Now a days, one of popular sectors in property business is trade center development. These trade centers exist mostly in big and high populated cities such as: Jakarta, Bandung or Surabaya in Indonesia. The existence of trade center gives customer better choice by single visit because there are many merchants that offer similar products in single trade center. Many trade centers specialize or focus on specific commodities such as: furniture, home appliance, electronics or building materials. So, it is easier for customer to find products that he need. For example, if customer wants to buy electronic goods, he will go to trade center A. Meanwhile, if this customer wants to buy furniture products, he will go to trade center B.

For some product classes such as furniture or electronics, delivery service is needed. It is because customer cannot bring the product that he bought by his own vehicle. Merchants usually have their own delivery unit. In one side having its own delivery unit makes the merchant can deliver products independently. In the other side having delivery unit needs investment, operational and maintenance costs.

There are some problems in having own delivery unit. The first problem is that each merchant usually has limited vehicles and in many cases, each merchant has only one vehicle. So, when the vehicle is unavailable, merchant cannot deliver products that have been bought by the customer until the vehicle is available. In many cases, customer will cancel the transaction and move to other merchants. Besides vehicle having its own delivery unit makes merchant must hire driver and assistant. When the driver or assistant is unavailable, merchant will face similar problem.

The second problem is delivery unit utility. There are days that merchant grabs large number of transactions. In this situation, the utility of its delivery unit is high and it can cover the delivery unit cost. Unfortunately, there are days that the number of transactions is low. In this situation, the utility of its delivery unit is low.

The third problem is delivery time. Merchant cannot predict the delivery location. In many cases, merchants must deliver more than one orders that their locations are far from each others. Even merchant can charge additional delivery cost to the customer, the delivery time to complete the all packages will be longer.

Based on these problems, it will be better that there is a company or delivery service that handles the delivery needs for merchants in trade center. By outsourcing the delivery activity to this company, merchants can solve these problems and focus on increasing sales. The delivery cost will be charged to the customer.

The similar condition occurs by the raising of online motorcycle taxi service in Indonesia. In Indonesia, these companies, for example, Gojek and Grab offer local courier service (Anonymous, 2016; Nurbianto, 2018), especially, for food delivery. In many cases, this service is proven in not only solving the food merchant problem in delivering 
orders but also increasing sales and keeps the driver busy (Davis, 2018). This condition not only occurs in food merchant that does not have delivery unit. Popular food merchants such as: Pizza Hut, McDonald and KFC also accept this service. Many customers also prefer to use third party delivery service rather than merchant's own delivery service because of availability problem. Besides, by using third party delivery service, the ordered food can be delivered faster.

Unfortunately, the existing local courier service model cannot be implemented directly in trade center based delivery system because trade center based delivery system has its own characteristics that have not been covered by the existing models. First, as it has been explained in our previous researches, the existing model cannot covers multi destinations or multi orders in single shipment. Second, even company such as Gojek has mini truck fleet for bigger package (Hafiz, 2015), because this service cannot handle more than one packages in single shipment, the delivery cost will be expensive.

Based on these problems, in this research, we propose new delivery service model that is suit for merchant characteristics in a trade center. This model is developed by adopting shortest path concept as its basis. This shortest path concept is chosen because this concept has been used widely in solving routing problem. Zyane et al. (2014) observed the performance of shortest path routing algorithm in optical WDM network. Dzida et al. (2008) proposed new three methods in optimizing shortest path-least cost routing in IP network. Zou et al. (2014) studied the shortest path routing in dynamic multi hop networks. Bertsekas (1979) developed dynamic model for shortest path routing in multiple destinations network.

Problems in existing merchant owned delivery service: It is common that merchants in any trade centers have their own delivery service, especially, for business sector that sell heavy goods such as furniture, building material and electronics. There are some reasons for this condition. First, they must deliver the sold goods to the customer because customer cannot pickup his purchased goods by himself. Second, by having his own delivery unit, merchant has full control of his delivery units. Third, there is not any collaboration or coordination between merchants even they are close to each others. This condition also occurs in many trade centers that merchant location is side by side with other merchants. Unfortunately, there are problems in this situation.

The first problem is there is inefficiency in travel distance and travel time when there is not any

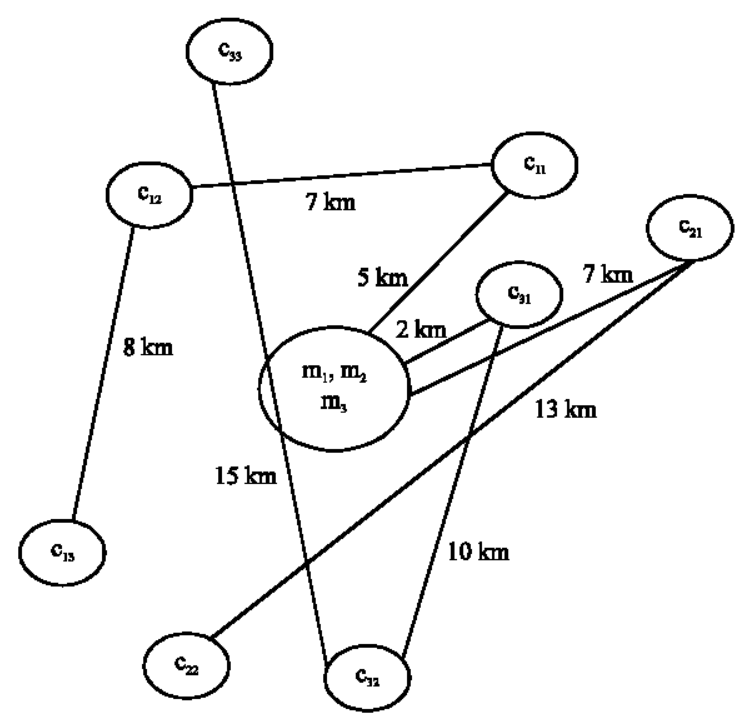

Fig. 1: Non collaboration delivery sequence

collaboration or coordination among merchants in delivering goods. The illustration is as follows. Suppose that there are three merchants in a trade center, $\mathrm{m}_{1}, \mathrm{~m}_{2}$ and $\mathrm{m}_{3}$. Merchant $\mathrm{m}_{1}$ must deliver products to customers: $\mathrm{c}_{11}-\mathrm{c}_{13}$. Merchant $\mathrm{m}_{2}$ must deliver products to customers: $\mathrm{c}_{21}$ and $\mathrm{c}_{22}$. Merchant $\mathrm{m}_{3}$ must deliver products to customers: $\mathrm{c}_{31}-\mathrm{c}_{33}$. The visualization of this illustration is shown in Fig. 1. Suppose that the vehicle speed is $24 \mathrm{~km} / \mathrm{h}$ or $400 \mathrm{~m} / \mathrm{min}$ and the installation time is $30 \mathrm{~min}$ per visit.

The explanation of this scenario is as follows. The sequence of $\mathrm{m}_{1}$ delivery unit is $\left\{\mathrm{c}_{11}-\mathrm{c}_{13}\right\}$ and it takes $20 \mathrm{~km}$ travel distance or $50 \mathrm{~min}$ travel time. Because it visits three locations then the total installation time is $90 \mathrm{~min}$. So, the total delivery time for $m_{1}$ is $140 \mathrm{~min}$. The sequence of $m_{2}$ delivery unit is $\left\{\mathrm{c}_{21}, \mathrm{c}_{22}\right\}$ and it takes $20 \mathrm{~km}$ travel distance or $50 \mathrm{~min}$ travel time. Because it visits two locations then the total installation time is $60 \mathrm{~min}$. So, the total delivery time for $\mathrm{m}_{2}$ is $110 \mathrm{~min}$. The sequence of $\mathrm{m}_{3}$ delivery unit is $\left\{\mathrm{c}_{31}-\mathrm{c}_{33}\right\}$ and it takes $27 \mathrm{~km}$ travel distance or $67.5 \mathrm{~min}$ travel time. Because it visits three locations then the total installation time is $90 \mathrm{~min}$. So, the total delivery time for $\mathrm{m}_{3}$ is $157.5 \mathrm{~min}$. The total travel distance for all merchants then is $67 \mathrm{~km}$ and the total delivery time for all merchants is $407.5 \mathrm{~min}$.

Based on the illustration, it is shown that there is inefficiency. Based on the closeness to their neighbor, these destinations can be grouped into three clusters. First cluster contains $\mathrm{c}_{11}-\mathrm{c}_{31}$. The second cluster contains $\mathrm{c}_{12}$ and $\mathrm{c}_{33}$. The third cluster contains $\mathrm{c}_{13}-\mathrm{c}_{32}$. Based on these clusters, the delivery scenario is shown in Fig. 2. 


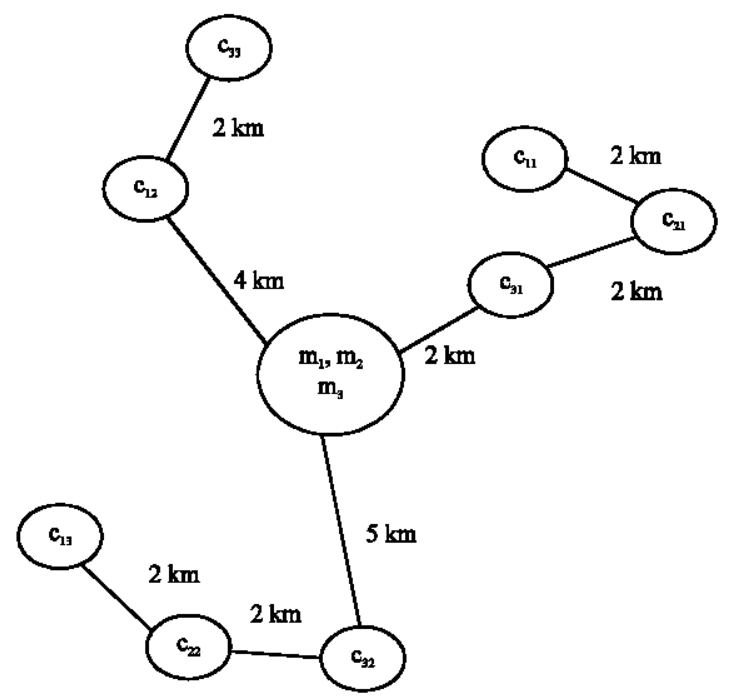

Fig. 2: Collaboration delivery sequence

Based on the collaborative scenario, the delivery service will travel shorter than the non collaborative one. The first group route is $\left\{\mathrm{c}_{31}-\mathrm{c}_{11}\right\}$. The travel distance is $6 \mathrm{~km}$ or $15 \mathrm{~min}$ travel time. The second group route is $\left\{\mathrm{c}_{12}, \mathrm{c}_{33}\right\}$. The travel distance is $6 \mathrm{~km}$ or $15 \mathrm{~min}$ travel distance. The third group route is $\left\{\mathrm{c}_{32}-\mathrm{c}_{13}\right\}$. The travel distance is $9 \mathrm{~km}$ or $22.5 \mathrm{~min}$ travel time. So, the total travel distance is $21 \mathrm{~km}$. Comparing to the first scenario, the total travel time of the second scenario is only $31.34 \%$ from the first scenario.

Based on the explanation above, there is inefficiency problem in non collaborative or non coordinated scenario in delivering goods. In the other side, there is efficiency opportunity when there is coordination and collaboration in delivering the sold goods to the customers.

\section{MATERIALS AND METHODS}

Proposed model: In this research, we propose the coordinated delivery system in a trade center. It is assumed that there is single delivery system company that handles all of shipments from the merchants in the trade center. This company has several delivery vehicles or units. When a merchant closes a transaction with the customer, this merchant will create delivery order to the company, so that, the company will deliver the goods to the specified destination.

The shipment model is scheduled shipment. It means that the delivery orders will be collected for some period. After the collecting session is closed, then the company will manage and dispatch the orders to the available vehicle. Then, the vehicle will deliver the goods at the delivery session. For example, all orders that are created today will be delivered tomorrow. The scheduled shipment is chosen rather than instant shipment because by choosing scheduled shipment, a vehicle can deliver more than one orders in single delivery session.

The nearest destination method that is adopted in this research is not greedy search method such as A Star or Best First Search. The reason is even the greedy search has been adopted in many routing process, this method consume heavy computation (Keller and Poli, 2008; Stojmenovic et al., 2000).

In this research, the total travel time $\left(t_{\text {travel }}\right)$ for vehicle contains three parts: delivery time $\left(\mathrm{t}_{\mathrm{del}}\right)$, installation time $\left(t_{\text {ins }}\right)$ and return time $\left(t_{\text {ret }}\right)$. Delivery time is the time that is spent for the vehicle to travel from its current position to the next delivery destination. Installation time is time that is needed to install the goods at the destination location. Returning time is the time that is needed to travel from its last destination to the trade center or base. This total time can be formulized in Eq. 1:

$$
\mathrm{t}_{\mathrm{tavel}}=\mathrm{t}_{\mathrm{del}}+\mathrm{t}_{\text {ins }}+\mathrm{t}_{\mathrm{ret}}
$$

Suppose that the number of destinations that must be visited by the vehicle is represented by $n$. The position of the vehicle is represented by $\mathrm{p}_{\text {veh. }}$. The destination location is represented by $\mathrm{p}_{\text {des. }}$. At the beginning or at step 0 , the $\mathrm{p}_{\text {veh }}(0)$ is at the base or trade center. Variable s represents the step. So, the vehicle position at certain step is determined by using Eq. 2. Vehicle delivery distance at certain step is determined by using Eq. 3. Vehicle delivery time at certain step is determined by using Eq. 4. Vehicle installation time at certain step is determined by using Eq. 5:

$$
\begin{gathered}
\mathrm{p}_{\text {veh }}(\mathrm{s})=\left\{\begin{array}{c}
\mathrm{p}_{\text {des }}(\mathrm{s}) \mathrm{s}>0 \\
\mathrm{p}_{\text {base }} \mathrm{s}=0
\end{array}\right. \\
\mathrm{d}_{\text {del }}(\mathrm{s})=\sum_{\mathrm{i}=1}^{s}\left\|\mathrm{p}_{\text {des }}(\mathrm{i})-\mathrm{p}_{\text {veh }}(\mathrm{i}-1)\right\| \\
\mathrm{t}_{\text {del }}(\mathrm{s})=\frac{\mathrm{d}_{\text {del }}(\mathrm{s})}{\mathrm{v}} \\
\mathrm{t}_{\text {ins }}(\mathrm{s})=\sum_{\mathrm{i}=1}^{s} \mathrm{t}_{\text {insunique }}(\mathrm{i})
\end{gathered}
$$

The explanation of Eq. 2-5 is as follows. In Eq. 2, the vehicle position at certain step is the destination location of this step except at step 0. At step 0, the vehicle position is at the base. In Eq. 3, the delivery distance that 
has been acquired by vehicle at certain step is the summation of the distance between vehicle previous position and the destination location from step 1 to the specified step. In Eq. 4, the delivery time that has been acquire by the vehicle certain step is the division between the delivery distance at specified step and the vehicle average speed. In Eq. 5, the installation time that has been acquired at certain step is the summation of the unique installation time at every step ( $\left.\mathrm{t}_{\text {insunique }}\right)$ from step 1 to specified step.

After all of goods have been delivered, then the vehicle will return to the base. The return distance $\left(\mathrm{d}_{\mathrm{ret}}\right)$ is determined by using Eq. 6. The return time $\left(t_{\text {ret }}\right)$ is determined by using Eq. 7. In Eq. 6, it is shown that the return distance is the distance between the last destination location and the base. In Eq. 7, it is shown that the return time is the division between return distance and the vehicle average speed (v):

$$
\begin{gathered}
\mathrm{d}_{\mathrm{ret}}=\left\|\mathrm{p}_{\text {des }}(\mathrm{n})-\mathrm{p}_{\text {base }}\right\| \\
\mathrm{t}_{\mathrm{ret}}=\frac{\mathrm{d}_{\mathrm{ret}}}{\mathrm{v}}
\end{gathered}
$$

In this research, there are two parameters those are being concerned in determining vehicle next destinations. The first parameter is the distance between vehicle current position and the destination. The second parameter is number of goods that must be delivered.

Based on distance factor, vehicle will choose the destination that its location is the nearest to its current location for the next destination. The purpose is to reach shortest delivery distance with lower computation rather than using greedy search. In this research, different to the previous research, observation area is not implemented. So, vehicle will choose the nearest destination even its location is far from the vehicle.

Based on the number of goods factor, the current vehicle will deliver to the destination only if the available slot is still enough. Even a destination is the nearest one, if the number of goods that must be delivered exceeds, the vehicle will not deliver to this destination.

The example is as follows. Suppose that there are seven destinations that the sold goods have not been delivered. These destinations can be represented as $\left\{\operatorname{des}_{1}, \operatorname{des}_{3} \operatorname{des}_{3} \ldots, \operatorname{des}\right\}$. Their location relative to the current vehicle position is shown in Fig. 3. The number of goods that must be picked up is shown in Table 1 .

The selected destination process is as follows. Suppose that the vehicle's number of available spaces is 3 units. It means that this vehicle can carry maximum 3 units. So, destination 1-6 can be selected as the next

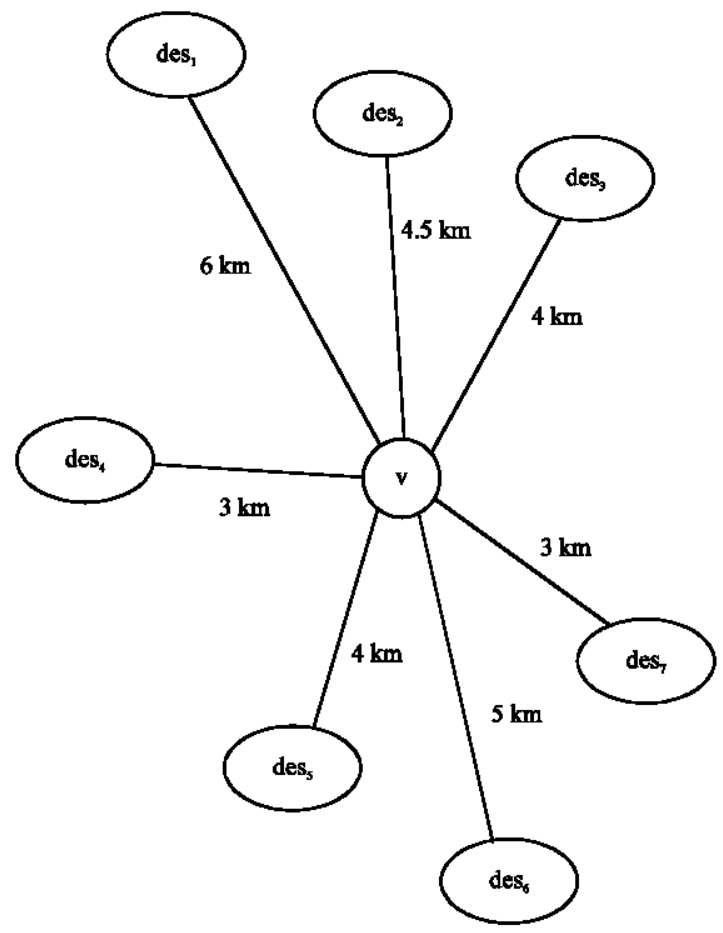

Fig. 3: Selecting next destination

\begin{tabular}{lcc}
\multicolumn{2}{l}{ Table 1: Destination parameters } \\
Delivery order & $\mathrm{d}_{\text {des }}(\mathrm{km})$ & $\mathrm{n}_{\text {gands }}$ (unit) \\
\hline 1 & 6 & 1 \\
2 & 4.5 & 2 \\
3 & 4 & 1 \\
4 & 3 & 3 \\
5 & 4 & 3 \\
6 & 5 & 2 \\
7 & 3 & 4 \\
\hline
\end{tabular}

destination. Destination 7 cannot be selected because the number of goods that must be delivered in destination 7 is more than 3 units. Among these possible destinations, the next destination will be destination 4 because this destination is the nearest one.

The selected destination will be different if the vehicle's number of available spaces is 2 units. It means that the possible destinations are destination 1-6. So, the next destination will be destination 3 . It is because this destination is the nearest one among possible destinations.

Based on the explanation above, the dispatch process is described as follows. The dispatch process will run until all delivery orders are allocated. At the beginning, the first vehicle is created or activated. As long as this vehicle travel time is less than the maximum travel time, this vehicle can get more order to be executed. When this active vehicle's travel time exceeds the maximum travel time then this vehicle will be deactivated and then next new vehicle will be created or be activated. This process algorithm is shown in Fig. 4. 


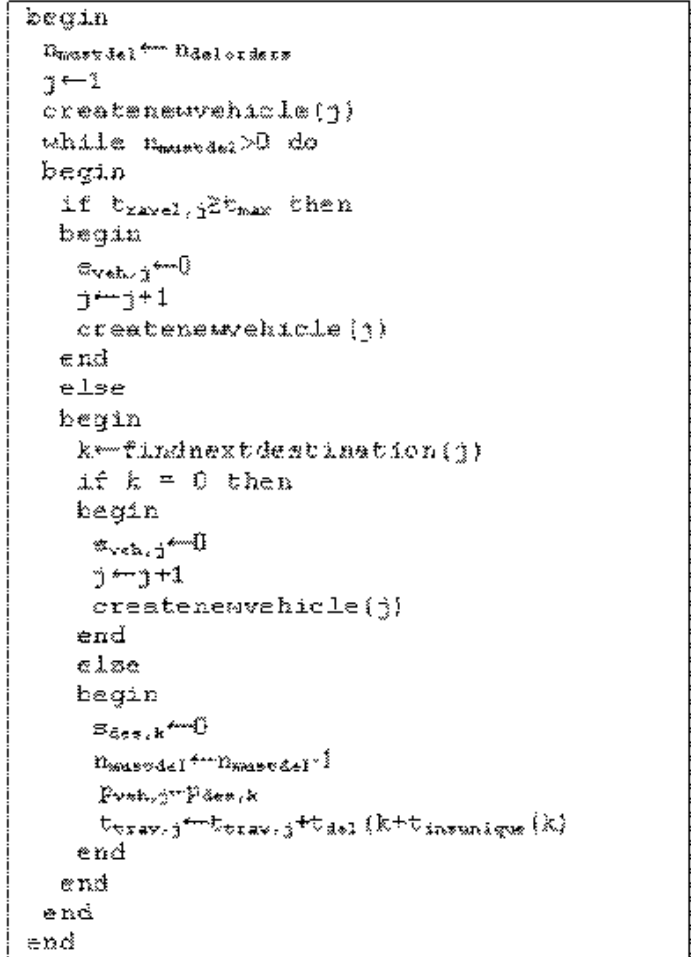

Fig. 4: Main dispatch process algorithm

Besides vehicle activating and deactivating processes, dispatching process also occurs. Dispatching process occurs as long as next destination for this vehicle can be found. This process is done by using findnextdestination procedure. If the procedure is failed to find the next destination then this vehicle is also deactivated. If the next destination is found then some processes are occurs. First, the status of the selected destination will be set 0 which means this destination has been allocated. Second, the number of orders that must be delivered is reduced by 1 . Third, the current vehicle position will be set at the selected destination position. The vehicle travel time is updated.

The find next destination procedure is divided into two processes. The first process is selecting the possible candidates. The second process is finding the nearest destination among possible candidates. The first process algorithm is shown in Fig. 5. The second process algorithm is shown in Fig. 6.

In candidate selection algorithm, some new variables are used. Variable $A_{\text {cand }}$ represents a set or array that contains possible destinations. Variable $\mathfrak{n}_{\text {rgoods }}$ represents the number of goods of the specified order that must be delivered. Variable $n_{a v}$ represents the number of available spaces or slots in the specified vehicle. In Fig. 5, the find nearest destination procedure is procedure that

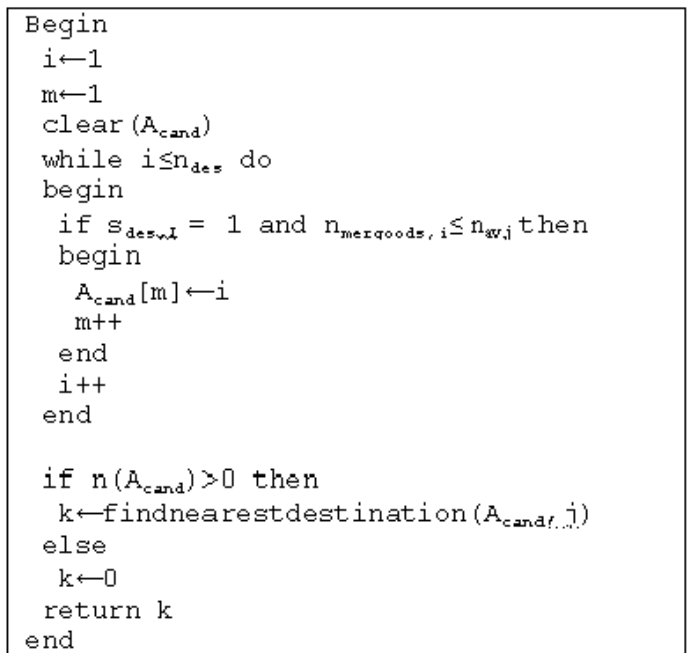

Fig. 5: Candidate selection algorithm

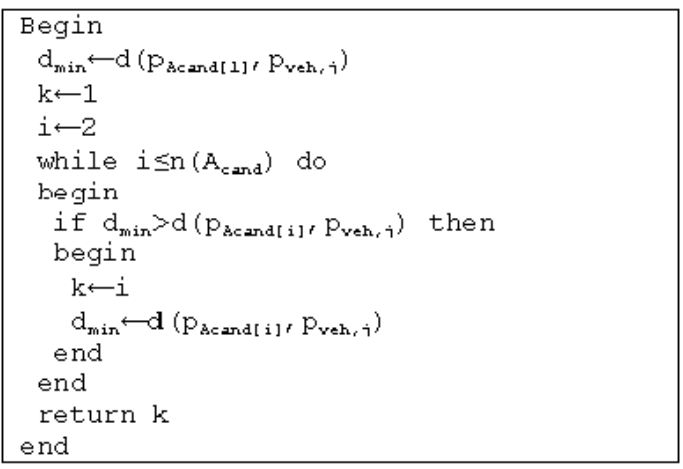

Fig. 6: Nearest destination algorithm

is used to find the nearest destination among candidates within the set $A_{\text {cand. }}$. This procedure is called only if the number of candidates in set $A_{\text {cand }}$ is more than one. The detailed process or algorithm of the nearest destination finding is shown in Fig. 6 .

In the nearest destination algorithm, there are some new variables. Variable $d_{\min }$ represents the current nearest distance. Variable $\mathrm{k}$ represents the current nearest destination. These variables values will be updated only if there is destination that its location is nearer than the current destination location.

\section{RESULTS AND DISCUSSION}

After the model has been implemented into simulation application, then several simulation sessions are run to observe the model performance. There are two goals in doing the test. The first goal is observing the relation between the adjusted parameters and the 
Table 2: Adjusted parameters default value

\begin{tabular}{|c|c|}
\hline Parameters & Default values \\
\hline $\mathrm{n}_{\text {mer rhants }}$ & 50 units \\
\hline $\mathrm{n}_{\mathrm{av} \text { delorders }}$ & 3 units \\
\hline $\mathrm{n}_{\mathrm{av} \text { _goods }}^{-}$ & 2 units \\
\hline $\mathrm{V}$ & $300 \mathrm{~m} / \mathrm{sec}$ \\
\hline $\mathrm{t}_{\mathrm{av} \text { inst }}$ & $30 \mathrm{~min}$ \\
\hline
\end{tabular}

Table 3: Relation between $\mathrm{n}_{\text {merhhants }}$ and observed parameters in non coordinated model

\begin{tabular}{lccc}
\hline $\mathrm{n}_{\text {merchants }}$ & $\mathrm{d}_{\text {lot tavel }}(\mathrm{km})$ & $\mathrm{t}_{\text {ot tavel }}(\mathrm{min})$ & $\mathrm{r}_{\text {succes }}(\%)$ \\
10 & 228.60 & 1461.80 & 95.60 \\
20 & 407.20 & 2679.80 & 97.60 \\
30 & 600.00 & 3960.80 & 98.80 \\
40 & 819.80 & 5339.60 & 96.80 \\
50 & 1025.80 & 6656.40 & 97.40 \\
60 & 1256.60 & 8130.60 & 98.60 \\
70 & 1441.10 & 9355.10 & 97.30 \\
80 & 1579.80 & 10402.70 & 97.20 \\
90 & 1834.30 & 12365.10 & 96.80 \\
100 & 2007.00 & 13073.20 & 97.40 \\
\hline
\end{tabular}

observed parameters. The second goal is comparing the performance between the proposed coordinated model and the existing non coordinated model.

The tests are done by adjusting some parameters: the number of merchants ( $\mathrm{n}_{\text {merchants }}$ ), average number of delivery orders $\left(\mathrm{n}_{\mathrm{av}-\mathrm{dellorders}}\right)$, average number of goods that must be delivered in a single delivery orders $\left(\mathrm{n}_{\mathrm{av} g \text { goods }}\right)$, the vehicle speed (v) and the average installation time $\left(\mathrm{t}_{\mathrm{av} \text { inst }}\right)$. When a parameter is adjusted in some range, other parameters are set at default value. The default value of these adjusted parameters is shown in Table 2 .

The first test is observing the relation between number of merchants and the observed parameters. The number of merchants is set from 10-100 units with step size is 10 units. Other adjusted parameters are set at default value. The simulation result that uses non coordinated model is shown in Table 3. The simulation result that uses proposed coordinated model is shown in Table 4.

Based on data in Table 3, it is shown that when the non coordinated model is implemented, the increasing of number of merchants makes the total travel distance and total travel time increase linearly. Meanwhile, the increasing of the number of merchants does not affect the success ratio. The success ratio tends to fluctuate with small ripple. This result is rational because higher number of merchants makes the number of orders that must be delivered increases.

Based on data in Table 4, it is shown that the increasing number of merchants similar to the non coordinated model, the increasing of the number of merchants makes the total travel distance, total travel time and number of vehicles tends to increase. But, there is fluctuation during the increasing trend. When the increasing number of merchants is not significant,
Table 4: Relation between $n_{\text {merchants }}$ and observed parameters in coordinated model

\begin{tabular}{lccc}
\hline $\mathrm{n}_{\text {mexchants }}$ & $\mathrm{d}_{\text {tot tavel }}(\mathrm{km})$ & $\mathrm{t}_{\text {tot travel }}(\min )$ & $\mathrm{n}_{\text {veh }}$ (unit) \\
10 & 48.60 & 604.40 & 2.600 \\
20 & 69.00 & 955.40 & 4.200 \\
30 & 123.80 & 1787.20 & 7.400 \\
40 & 96.60 & 1605.80 & 7.200 \\
50 & 188.20 & 2909.60 & 12.60 \\
60 & 79.20 & 1361.80 & 6.600 \\
70 & 249.70 & 3787.00 & 17.20 \\
80 & 233.50 & 3720.80 & 17.00 \\
90 & 161.30 & 3171.00 & 13.70 \\
100 & 253.20 & 4114.60 & 19.20 \\
\hline
\end{tabular}

Table 5: Relation between $\mathrm{n}_{\mathrm{av} \text { _delorders }}$ and observed parameters in non coordinated model

\begin{tabular}{lccc}
\hline $\mathrm{n}_{\text {av delorders }}$ & $\mathrm{d}_{\text {tot tavel }}(\mathrm{km})$ & $\mathrm{t}_{\text {tot travel }}(\mathrm{min})$ & $\mathrm{r}_{\text {srcess }}(\%)$ \\
\hline 1 & 583.30 & 3380.70 & 100.00 \\
2 & 781.50 & 4757.30 & 100.00 \\
3 & 985.20 & 6548.60 & 97.10 \\
4 & 1193.20 & 8316.00 & 91.70 \\
5 & 1240.00 & 9179.90 & 85.20 \\
\hline
\end{tabular}

Table 6: Relation between $n_{\mathrm{av} \text { delorders }}$ and observed parameters in coordinated model

\begin{tabular}{lccc}
\hline $\mathrm{n}_{\text {mexchants }}$ & $\mathrm{d}_{\text {tot tavel }}(\mathrm{km})$ & $\mathrm{t}_{\text {tot tavel }}(\min )$ & $\mathrm{n}_{\text {veh }}$ (unit) \\
\hline 1 & 73.50 & 956.80 & 4.30 \\
2 & 46.60 & 808.50 & 3.80 \\
3 & 145.80 & 2314.40 & 10.50 \\
4 & 196.90 & 3047.10 & 14.10 \\
5 & 97.70 & 2001.30 & 9.20 \\
\hline
\end{tabular}

the observed parameters does not always increase. Especially, in number of vehicles parameter, this observed parameter value is also depended on the relation between vehicle capacity and the number of goods that must be delivered in single delivery order.

Comparing data in Table 3 and 4, the coordinated model performs better result rather than the non coordinated one in any number of merchants. At same number of merchants, by using coordinated model, the total travel distance is lower than by using non coordinated one. This condition is also similar in total travel time parameter.

The second test is observing the relation between average number of delivery orders for each merchant $\left(\mathrm{n}_{\mathrm{ay} \_ \text {delorders }}\right)$ and the observed parameters. The $\mathrm{n}_{\mathrm{av} \_ \text {delorders }}$ is set from 1-5 units with step size is 1 units. Other adjusted parameters are set at default value. The simulation result that uses non coordinated model is shown in Table 5. The simulation result that uses proposed coordinated model is shown in Table 6.

Based on data in Table 5, it is shown that when the non coordinated model is implemented, the increasing of the number of delivery orders makes the total travel distance and total travel time increase too. The growth of these two parameters is linear. Meanwhile, the success ratio is reduced when the number of delivery orders increase. This condition is rational because in non 
Table 7: Relation between $n_{\text {av goods }}$ and observed parameters in non coordinated model

\begin{tabular}{lccc}
\hline $\mathrm{n}_{\text {sv soeds }}$ & $\mathrm{d}_{\text {tot tavel }}(\mathrm{km})$ & $\mathrm{t}_{\text {ot tavel }}(\min )$ & $\mathrm{r}_{\text {success }}(\%)$ \\
\hline 1 & 1036.7 & 6852.8 & 100 \\
2 & 1021.9 & 6648.7 & 97.3 \\
3 & 945.9 & 6050.4 & 90.3 \\
4 & 861.6 & 5437 & 85.5 \\
5 & 795.5 & 5133 & 76.1 \\
\hline
\end{tabular}

Table 8: Relation between $\mathrm{n}_{\mathrm{uv} \text { goods }}$ and observed parameters in coordinated model

\begin{tabular}{lccc}
\hline $\mathrm{n}_{\text {avroods }}$ & $\mathrm{d}_{\text {tot tavel }}(\mathrm{km})$ & $\mathrm{t}_{\text {ot tarel }}(\min )$ & $\mathrm{n}_{\text {veh }}$ (unit) \\
\hline 1 & 92.1 & 1814.8 & 5.80 \\
2 & 171.0 & 2632.8 & 11.9 \\
3 & 187.6 & 2299.7 & 14.4 \\
4 & 284.4 & 2637.2 & 19.9 \\
5 & 200.6 & 2101.3 & 17.9 \\
\hline
\end{tabular}

coordinated model, when the number of delivery orders exceeds the vehicle capacity, the number of undelivered orders will increase.

Based on data in Table 6 , it is shown that when coordinated model is implemented, the increasing of the delivery orders in a single merchant makes all of the observed parameters tend to increase. But, the increasing trend is followed by fluctuation. The fluctuation is higher than in Table 4. It can be said, even the trend is positive, the small increasing in number of delivery orders in a single merchant does not always make the increasing in total travel distance, total travel time and number of vehicles.

By comparing data between Table 5 and 6 , it is shown that the coordinated model performs better than the non coordinated model in all number of delivery orders in a single merchants. When the system implements coordinated model, the total travel time and total travel distance is always lower than the non coordinated one.

The third test is observing the relation between average number of goods for each delivery order $\left(\mathrm{n}_{\mathrm{ay} \text { goods }}\right)$ and the observed parameters. The $\mathrm{n}_{\mathrm{ay} \text { goods }}$ is set from 1-5 units with step size is 1 units. Other adjusted parameters are set at default value. The simulation result that uses non coordinated model is shown in Table 7. The simulation result that uses proposed coordinated model is shown in Table 8.

Based on data in Table 7, it is shown that when the system implements non coordinated model, the increasing of the number of goods in single delivery order makes the total travel distance, total travel time and success ratio reduced. The increasing number of the goods does not mean the number of delivery orders increases. So with the same number of delivery orders, the increasing of number of goods increases the number of undelivered orders. That is why the total travel distance and total travel time are reduced too.
Table 9: Relation between vehicle speed and observed parameters in non coordinated model

\begin{tabular}{lccc}
\hline $\mathrm{v}(\mathrm{m} / \mathrm{min})$ & $\mathrm{d}_{\text {tot tavel }}(\mathrm{km})$ & $\mathrm{t}_{\text {tot travel }}(\mathrm{min})$ & $\mathrm{r}_{\text {succes }}(\%)$ \\
\hline 100 & 1026.9 & 13765.7 & 96.5 \\
200 & 1014.9 & 8391.1 & 97.4 \\
300 & 1023.1 & 6669.0 & 96.9 \\
400 & 1032.3 & 5824.2 & 97.8 \\
500 & 990.6 & 5050.8 & 97.3 \\
\hline
\end{tabular}

Table 10: Relation between vehicle speed and observed parameters in coordinated model

\begin{tabular}{lccc}
\hline $\mathrm{v}(\mathrm{m} / \mathrm{min})$ & $\mathrm{d}_{\text {tot tavel }}(\mathrm{km})$ & $\mathrm{t}_{\text {tot travel }}(\mathrm{min})$ & $\mathrm{n}_{\text {veh }}$ (unit) \\
\hline 100 & 91.1 & 2312.9 & 7.60 \\
200 & 122.0 & 2177.3 & 8.40 \\
300 & 191.1 & 2856.0 & 12.5 \\
400 & 145.1 & 2132.7 & 10.1 \\
500 & 150.4 & 1958.0 & 9.70 \\
\hline
\end{tabular}

Based on data in Table 8, it is shown that when the system implements coordinated model, the increasing of the number of goods in single delivery order makes the all of observed parameters increase too. The gradient of the increasing trend is low. The increasing trend is followed by small fluctuation.

By comparing data in Table 7 and 8 , the increasing of number of goods in single delivery order makes opposite result between the coordinated model and the non coordinated one. In non coordinated model, the increasing of the number of goods makes the total travel distance and the total travel time are reduced. Meanwhile, in coordinated model, the increasing of the number of goods increase the total travel distance and the total travel time.

The fourth test is observing the relation between vehicle speed (v) and the observed parameters. The speed is set from $100-500 \mathrm{~m} / \mathrm{min}$ with step size is 100 $\mathrm{m} / \mathrm{min}$. Other adjusted parameters are set at default value. The simulation result that uses non coordinated model is shown in Table 9. The simulation result that uses proposed coordinated model is shown in Table 10.

Based on data in Table 9, it is shown that when the non coordinated model is implemented, the increasing speed does not affect the total travel distance and the success ratio. Meanwhile, when the speed increased, the total travel time decreases.

Based on data in Table 10, it is shown that when the coordinated model is implemented, the increasing in speed does not affect the total travel distance and number of vehicles. Meanwhile, the increasing in speed makes the total travel time reduced.

By comparing data in Table 9 and 10 , it is shown that the coordinated model performs better than non coordinated one in any speed. When system implements coordinated model, the total travel distance is lower than when the system implements non coordinated model. This situation also occurs in total travel time parameters. 
Table 11: Relation between $t_{\mathrm{av} \text { inst }}$ and observed parameters in non coordinated model

\begin{tabular}{lccc}
\hline $\mathrm{t}_{\text {avinst }}(\mathrm{m} / \mathrm{min})$ & $\mathrm{d}_{\text {tot tavel }}(\mathrm{km})$ & $\mathrm{t}_{\text {tot travel }}(\mathrm{min})$ & $\mathrm{r}_{\text {success }}(\%)$ \\
10 & 988.8 & 4239.3 & 97.2 \\
20 & 1016.9 & 5655.7 & 96.9 \\
30 & 1032.9 & 6977.9 & 97.2 \\
40 & 1016.0 & 7860.2 & 97.3 \\
50 & 1001.5 & 8967.6 & 96.6 \\
60 & 1013.1 & 9848.5 & 96.6 \\
\hline
\end{tabular}

Table 12: Relation between $\mathrm{t}_{\mathrm{av} \text { _int }}$ and observed parameters in coordinated model

\begin{tabular}{lccr}
\hline $\mathrm{t}_{\text {avinst }}(\mathrm{m} / \mathrm{min})$ & $\mathrm{d}_{\text {tot tavel }}(\mathrm{km})$ & $\mathrm{t}_{\text {ot tavel }}(\mathrm{min})$ & $\mathrm{n}_{\text {veh }}$ (unit) \\
\hline 10 & 93.2 & 674.4 & 7 \\
20 & 161.2 & 1828.3 & 11.4 \\
30 & 138.3 & 2213.8 & 10 \\
40 & 122.2 & 2561.8 & 9 \\
50 & 165.6 & 4173.5 & 11.6 \\
60 & 147.3 & 4165.7 & 10.8 \\
\hline
\end{tabular}

The fifth test is observing the relation between average installation time $\left(t_{\mathrm{av} \text { inst }}\right)$ and the observed parameters. The $t_{a v \_ \text {inst }}$ is set from 10 to 60 minutes with step size is $10 \mathrm{~min}$. Other adjusted parameters are set at default value. The simulation result that uses non coordinated model is shown in Table 11. The simulation result that uses proposed coordinated model is shown in Table 12.

Based on data in Table 11 and 12, when the system implements non coordinated or coordinated model, the increasing of the installation time affects only the total travel time. In non coordinated model, the change in installation time does not affect the total travel distance or the success ratio. In coordinated model, the change in installation time does not affect the total travel distance or the number of vehicles. By comparing data between Table 11 and 12, the coordinated model performs better than the non coordinated one.

\section{CONCLUSION}

Based on the explanation above, the proposed coordinated model has been implemented into the trade center based delivery service simulation to simulate the delivery service process. The model is developed based on the nearest destination method. Based on the test result, it is shown that the proposed coordinated model performs better than existing non coordinated one, especially, in total travel distance and total travel time parameters.

The other research findings are follows. In coordinated model, the increasing of the number of merchants, the increasing of the number of delivery orders and the number of goods in single delivery order makes the total travel distance, total travel time and number of vehicles increase. The increasing of speed reduces the total travel time. The increasing of installation time increases the total travel time.

In non coordinated model, the increasing of the number of merchants increases the total travel time and total travel distance. The increasing of delivery orders in a single merchant increase the total travel time and total travel distance but reduces the success ratio. The increasing of number of goods in single delivery order reduces all of observed parameters. Similar to the coordinated model, the increasing of speed reduces the total travel time and the increasing of installation time increases the total travel time.

There are many research potentials in developing logistic model, especially, in delivery system. Information and computation technologies make the delivery system more efficient. This research can be implemented in situation which customer cannot request the delivery time. So, improving this system, so that, coordinated model can cover delivery time request is challenging.

\section{IMPLEMENTATIONS}

The proposed model then is implemented into trade center based courier system simulation application. The simulation is developed by using PHP language, so that, this is a web based application. This platform is chosen because of its simplicity rather than other platform such as Java.

In this simulation application, a virtual world is developed. This virtual world represents a virtual medium city. The city size is $15 \mathrm{~km}$ length and $15 \mathrm{~km}$ width. The city shape is square.

The trade center assumption is as follows. The trade center is at the center of the city. The trade center consists of merchants that sell similar products, so that, the products can be delivered together. For non collaborative and non coordinated delivery service, each merchant has one delivery unit. The vehicle unit is a mini truck. The product is electronics or home appliances, so that, the maximum capacity of the vehicle is ten goods. In this simulation, the electronic product is not specified, whether it is refrigerator, washing machine, air conditioner or other home appliance. The vehicle's maximum travel time is $8 \mathrm{~h}$.

The simulation session runs as follows. Before the simulation runs, user must determine some parameters: the number of merchants $\left(\mathrm{n}_{\text {merhants }}\right)$, average number of delivery orders $\left(\mathrm{n}_{\mathrm{av}}\right.$ delorders $)$, average number of goods that must be delivered in a single delivery orders $\left(\mathrm{n}_{\mathrm{av} \_ \text {goods }}\right)$, the vehicle speed $(v)$ and the average installation time $\left(\mathrm{t}_{\mathrm{av}}\right.$ inst $)$. After the simulation adjusted parameters are set then the 
simulation can be run. The simulation session runs until all delivery orders are executed. After the simulation stops, the observed parameters are shown. The observed parameters include: total vehicles travel distance and total vehicles travel time. The success ratio $\left(r_{\text {success }}\right)$ is the additional observed parameters for non coordinated delivery service. The number of vehicles $\left(\mathrm{n}_{\mathrm{veh}}\right)$ that are needed to execute orders is the additional observed parameters for coordinated delivery service.

\section{REFERENCES}

Anonymous, 2016. Grab hits the road with GrabFood food delivery service. The Jakarta Post, Jakarta, Indonesia. http://www.thejakartapost.com/news/2016/05/02/grabhits-the-road-with-grabfood-food-delivery-service. html

Bertsekas, D.P., 1979. Dynamic models of shortest path routing algorithms for communication networks with multiple destinations. Proceedings of the IEEE 18th International Conference on Decision and Control Including the Symposium on Adaptive Processes Vol. 2, December 12-14, 1979, IEEE, Fort Lauderdale, Florida, USA., pp: 127-133.

Davis, J., 2018. Lesson from Go-Jek: Answer to Uber, grab. The Jakarta Post, Jakarta, Indonesia. http://www thejakartapost.com/academia/2018/04/18 /lesson-from-go-jek-answer-to-uber-grab.html

Dzida, M., M. Zagozdzon, M. Zotkiewicz, M.P. Pettersson and M. Pioro et al., 2008. Three methods for optimizing single-shortest path routing. Proceedings of the International Conference on Next Generation Internet Networks NGI, April 28-30, 2008, IEEE, Krakow, Poland, ISBN:978-1-4244-1784-1, pp: 61-68.
Hafiz, M.P.A., 2015. [Why many people reach go-box?]. Marketeers, South Jakarta, Indonesia. http://marketeers.com/mengapa-banyak-orangmenanti-go-box/

Keller, R.E. and R. Poli, 2008. Self-adaptive hyperheuristic and greedy search. Proceedings of the Joint International IEEE Congress on Evolutionary Computation and Computational Intelligence, June 1-6, 2008, IEEE, Hong Kong, China, ISBN: 978-1-4244-1822-0, pp: 3801-3808.

Nurbianto, B., 2018. Grab to operate in 120 Indonesian cities after Uber acquisition. The Jakarta Post, Jakarta, Indonesia. http://www.thejakartapost.com/ news/2018/04/06/grab-to-operate-in-1 20-indonesiancities-after-uber-acquisition.html

Stojmenovic, I., M. Russell and B. Vukojevic, 2000. Depth first search and location based localized routing and QoS routing in wireless networks. Proceedings of the 2000 International Conference on Parallel Processing, August 21-24, 2000, IEEE, Washington, DC, USA., ISBN:0-7695-0768-9, pp: 173-180.

Zou, Z., A. Proutiere and M. Johansson, 2014. Online shortest path routing: The value of information. Proceedings of the International Conference on American Control (ACC), June 4-6, 2014, IEEE, Portland, Oregon, ISBN:978-1-4799-3274-0, pp: 2142-2147.

Zyane, A., Z. Guennoun and O. Taous, 2014. Performance evaluation of shortest path routing algorithms in wide All-optical WDM networks. Proceedings of the 2014 International Conference on Multimedia Computing and Systems (ICMCS), April 14-16, 2014, IEEE, Marrakech, Morocco, ISBN:978-1-4799-3824-7, pp: 831-836. 